\title{
TSUNAMI INDUCED FORCES IN BRIDGES: LARGE-SCALE EXPERIMENTS AND THE ROLE OF AIR-ENTRAPMENT
}

\author{
Denis Istrati ${ }^{1}$, Ian G Buckle ${ }^{1}$, Pedro Lomonaco ${ }^{2}$, Solomon Yim $^{3}$, Ahmad Itani ${ }^{1}$
}

\begin{abstract}
In this study large scale hydraulic experiments of tsunami waves impacting a straight composite I-girder bridge were conducted in the LWF at Oregon State University. Both solitary waves and turbulent bores were tested and the experimental results revealed the existence of 4 different phases in the vertical force histories, among which is (i) a phase with a large applied moment and bridge rotation at the time of the first impact of the tsunami bore on the bridge, and (ii) a phase with a governing uplift mode of the bridge during the passage of the wave through the bridge. The first phase introduced the largest tensile forces in the offshore bearings and must be considered in order to prevent the progressive damage of the bearings. Moreover, the air-entrapment occurring in bridges with diaphragms was seen to (a) alter significantly the pattern of the applied pressures on the girders and below the deck in the internal chambers, (b) consistently increase the total uplift forces for all examined wave heights, and (3) cause a complex nonlinear wave-air interaction phenomenon with possibly significant 3D effects.
\end{abstract}

Keywords: large-scale experiments, tsunami waves; bridges; air-entrapment; nonlinear wave-air interaction

\section{INTRODUCTION}

Recent major earthquake events that occurred in the Indian Ocean (2004), Chile (2010) and Japan (2011) generated tsunami waves of significant heights, which inundated nearby coastal cities causing extreme destruction and loss of human lives. In the 2011 Tohoku earthquake in Japan approximately 100 bridges failed due to the tsunami inundation (EERI Report 2011). The main damage occurred in the connections of the superstructure to the substructure causing the bridge deck to be washed away. This damage pattern was observed for both bridges with concrete girders and diaphragms (e.g. Utatsu Bridge) as well as bridges with steel girders and cross-frames (e.g. Koizumi Bridge), as shown in Figure 1. These events demonstrated the vulnerability of coastal bridges to tsunami waves and triggered the response of the research community in an attempt to improve the understanding of tsunami inundation and the effects on structures.
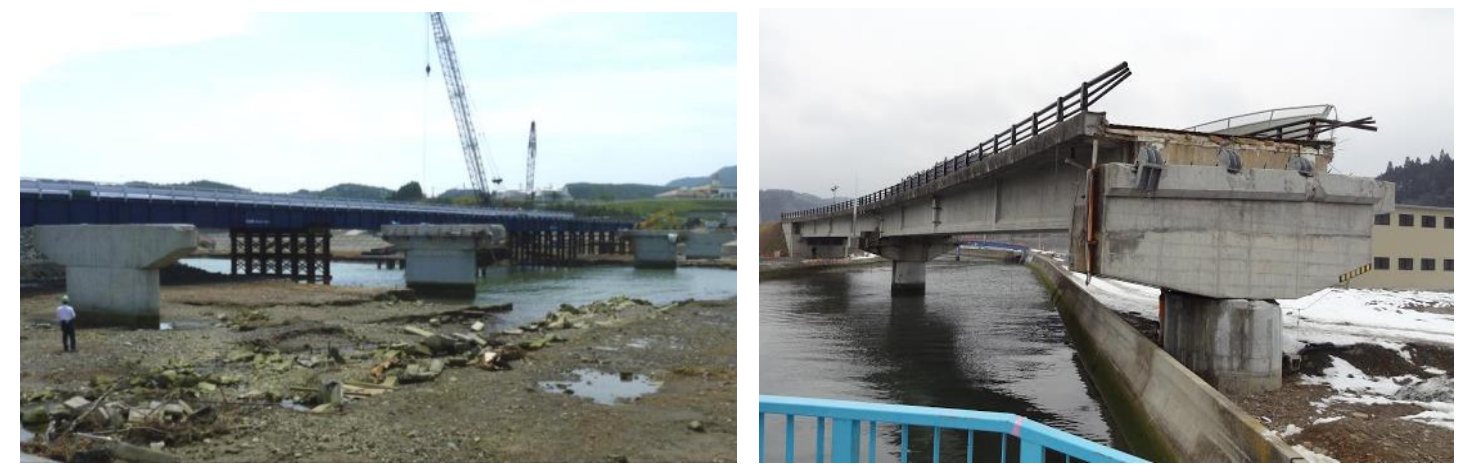

Figure 1. Damaged bridges after the 2011 tsunami in Japan: (a) Koizumi bridge on the left (from EERI Report 2011) and (b) Utatsu bridge on the right (from M. Yashinski)

Several interesting studies have been conducted to date including (i) on-site surveys and damage analysis (Kosa 2012, Kawashima 2012, Kawashima and Buckle 2013) (ii) small-scale experiments in wave flumes (Hayashi 2013, Lau et al 2011, Maruyama et al 2013) and (iii) numerical simulations (Hayatdavoodi et al 2015, Bricker and Nakayama 2014, Kataoka and Kaneko 2013, Yim et al 2011, Azadbakht 2013, Istrati and Buckle 2014). On-site investigations analyzed the failed bridges and revealed that the overflow can occur either in the form of transverse drag due to large horizontal wave forces or in the form of uplift and overturning due to the combination of large vertical and horizontal tsunami forces (Kawashima 2012, Kawashima and Buckle 2013).

\footnotetext{
${ }^{1}$ Department of Civil and Environmental Engineering, University of Nevada, Reno, 1664 N Virginia St, Reno, NV 89557, USA

2 O.H. Hinsdale Wave Research Laboratory, 3550 S.W. Jefferson Way, Corvallis, OR 97331, USA

${ }^{3}$ School of Civil \& Construction Engineering, 101 Kearney Hall, Oregon State University, Corvallis, OR 97331, USA
} 
Regarding the experimental studies, various researchers investigated the tsunami loads on flat slabs (Seiffert et al 2014), box shaped bridge decks (Hayashi 2013) and decks with girders (Lau et al 2011, Maruyama et al 2013 and Hoshikuma et al 2013) and in most cases both pressures and forces were measured. Most of these experiments were conducted at a small to medium scales ranging from 1:100 to $1: 20$ and the bridge models consisted of acrylic or wood decks supported rigidly either from the top or the bottom of the deck. To date the largest scale experiment was conducted by Bradner et al (2010) where they examined the performance of a 1:5 scaled pre-stressed bridge with rigid and flexible substructure, however the hydraulic tests were focused on hurricane waves and not tsunamis.

Another topic of interest in the coastal engineering community has been the trapped air between the girders of a bridge. McPherson (2008) studied experimentally the hurricane induced wave forces on a 1:20 scale bridge model and observed the existence of trapped air during the inundation of the bridge. He developed predictive force equations where he considered additional buoyancy due to the existence of air, assuming that $50 \%$ of the volume between girders were filled with air. Bricker and Nakayama (2014) who studied numerically the tsunami inundation of Utatsu Bridge in Japan, revealed that the trapped air between the girders increased the buoyancy of the bridge deck significantly resulting in the failure of the bridge. Hayatdavoodi et al (2014) noted that the trapped air increases the pressures below the bridge however it has not only a hydrostatic but also a hydrodynamic effect. Cuomo et al (2009) conducted hydraulic experiments of a bridge at 1:8 scale and observed that the holes in the bridge deck reduced the wave pressures on the deck slab but increased the ones on the longitudinal beams. The authors also noted the compression of the trapped air during the wave inundation acting as cushioning that reduces the max impulsive load and increases the load duration.

Azadbakht, M. (2013) investigated numerically the impact of hurricane waves and Seiffert et al (2015) investigated experimentally (1:35 scale) the impact of solitary waves on coastal bridges with trapped air and both observed that the air-entrapment can significantly alter the water flow field during the wave inundation causing a significant increase in the uplift force. Bozognia et al (2011) and Xu et al (2016) conducted numerical studies and observed that the air-vents could reduce significantly the uplift force.

\section{OBJECTIVE OF THIS STUDY}

Most of the experiments available in the literature have been conducted at a small-to-medium scale using very stiff bridge models that could not account for the actual bridge properties and dynamic characteristics (material, flexibility, inertia). In addition, small-scale experiments might be associated with significant scale effects since the atmospheric pressure cannot be scaled in the experiments (Martinelli et al 2010). Especially in the case that trapped air is compressed in a chamber significant distortion of the scale can occur (Takahashi et al 1985). These facts coupled with the fact that available numerical methods and most of the previous numerical studies have been validated with small scale experiments where the actual dynamic fluid-structure interaction (FSI) was not considered, demonstrate the need for large scale hydraulic experiments of tsunami wave impact on bridge models with realistic properties. Therefore, the main objectives of this project are to:

- Conduct at the largest possible scale hydraulic experiments of tsunami forces impacting a bridge with realistic behavior to minimize scale effects,

- Examine the difference in the bridge response when subjected to unbroken solitary waves and more realistic turbulent bores,

- Measure not only the total waves forces but also the distribution of these forces in the girder-tobent cap and bent cap-to-column connections in order to identify the failure mechanism of the connections and determine the max force that each connection has to be designed for,

- Shed light on the physics of the dynamic wave-air and wave-structure interactions and how they are affected by the dynamic characteristics of the bridge

- Identify the variation of tsunami loads for different types of bridges (e.g. bridges with cross-frames vs. bridges with diaphragms vs box-girder bridges),

- Develop a high quality database that can be used for (i) examining the accuracy of existing empirical predictive equations for tsunami loads, (ii) validating hydrodynamic models, available CFD methods and FSI capabilities of numerical codes, and (iii) development of recommendations and design guidelines for establishing tsunami-resilient bridges.

This paper will present results from two bridge configurations and provide observations and comments related to some of the objectives presented above. 


\section{EXPERIMENTAL SETUP}

\section{Bridge description}

For the hydraulic experiments conducted in this study a composite bridge model with four I-girders was designed and constructed at a 1:5 scale. The in-plane dimensions of the bridge deck are $3.45 \mathrm{~m}$ length and $1.94 \mathrm{~m}$ width. As shown in Fig. 2 the steel girders are connected with cross-frames at the end supports and at third points. Two shear connectors of $0.95 \mathrm{~cm}$ diameter have been welded on the flange of each girder every $5.1 \mathrm{~cm}$ down the length of the girders in order to achieve the composite behavior with the deck which was constructed with concrete and is reinforced with a steel wire $4 \times 4$ - D5xD5. The thickness of the slab is $5.1 \mathrm{~cm}$, the haunch is $1.0 \mathrm{~cm}$ and the height of the steel girders is $21.3 \mathrm{~cm}$.

The bridge model was connected to the bent caps with two different type of connections, rigid spacers and plain elastomeric bearings to allow for thermal expansion. The bearing dimensions were 6.5 $\mathrm{cm}$ diameter and $1.27 \mathrm{~cm}$ height. Shear keys were also designed to take the lateral earthquake load and transfer it to the bent caps. The bearings and the shear keys correspond to realistic flexible connections which allow rotations and vertical displacements of the bridge but restrict the horizontal displacements. Rigid connections that restrained all the degrees of freedom were also designed and comparison with the previous case demonstrated the role of the flexibility of the connections. The bridge and the rest of the structural components were designed according to the AASHTO LRFD Bridge Design Specifications (2012) assuming that the bridge was located in a Seismic Zone 3. The bridge and all the connecting elements were designed and constructed at the University of Nevada, Reno (Fig. 2) and then shipped to Oregon State University for testing in the Wave Flume. The hydrodynamic testing included 15 different configurations of a straight bridge and 4 configurations of a skew bridge, however this paper will present results from two straight bridge cases with elastomeric bearings, namely case ST2 that had cross-frames and case ST5 that had plywood diaphragms.
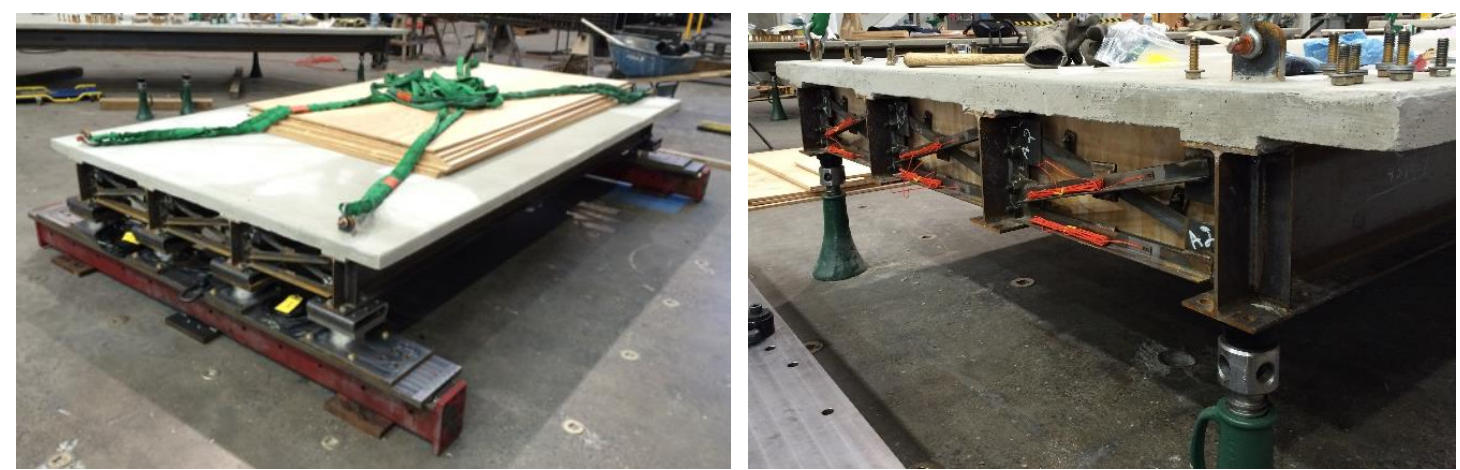

Figure 2. I-girder composite bridge with cross-frames (left) and attached plywood diaphragms (right) during the assembly in the Large Scale Structures Lab at the University of Nevada, Reno

\section{Test facility and flume bathymetry}

The experiments were conducted in the Large Wave Flume (LWF) at the O.H. Hinsdale Wave Research Laboratory (HWRL) at Oregon State University. The flume is $104.24 \mathrm{~m}$ long, $3.66 \mathrm{~m}$ wide, and $4.57 \mathrm{~m}$ deep. The maximum depth for tsunami-type wave generation is $2 \mathrm{~m}$, and the maximum wave height for this depth is $1.40 \mathrm{~m}$. The LWF is equipped with a piston-type dry-back wavemaker with a $4.2 \mathrm{~m}$ maximum stroke hydraulic actuator assembly and has a movable/adjustable bathymetry made of 20 square configurable concrete slabs. The flume includes a series of bolt-holes vertical patterns every $3.66 \mathrm{~m}$ along the flume for supporting test specimens as well as the concrete bathymetry slabs.

For this project, parametric CFD analyses of the whole flume with the bridge were conducted in LS-DYNA in order to identify the appropriate combination of slopes/bathymetry that will permit the testing of both unbroken solitary waves and bores and determine the optimum location of the bridge in the flume. A slope of 1:12 at the beginning, followed by a horizontal bathymetry $40.2 \mathrm{~m}$ long and another 1:12 slope at the end of the flume for dissipating waves was seen to be the most appropriate (Fig.3). The slope at the beginning will cause a decrease of the water depth which will influence the wave and as a result the wave height will increase during propagation due to shoaling and depending on the ratio of the wave height/water depth it will break and form a bore. In addition, the optimum location for the bridge was between bays 14 and 15, in order to allow for the bore to form after the wave breaking and still inundate the bridge (Fig.3). 


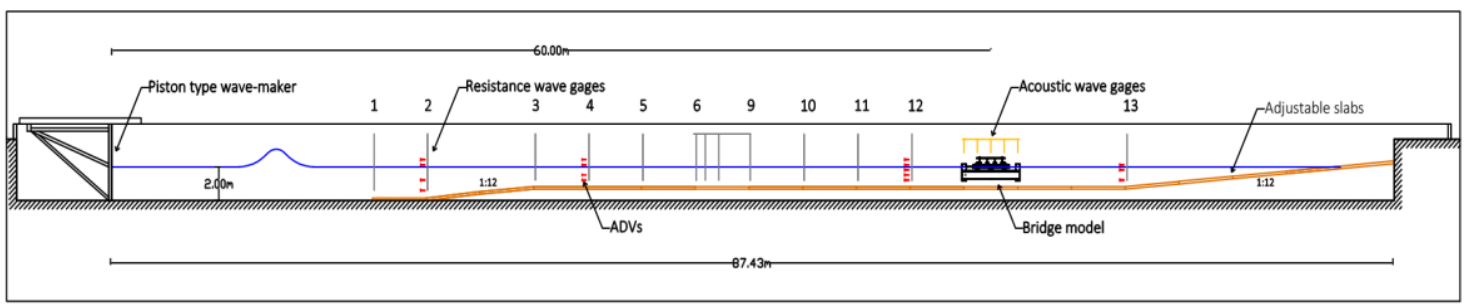

Figure 3. Cross-section of the Large Wave Flume at Oregon State University showing the bathymetry, bridge location and flume instrumentation

\section{Testing frame and wave matrix}

As shown in Fig.4, the bridge was installed on the red bent caps which were supported by a testing frame consisting of two black beams and two brackets, which was bolted to the flume walls. The experimental setup also consisted of rails with small friction bolted on top of the black beams, carriages connected to the rails and the load cells below the red bent caps, load cells on top of the bent caps that were connected to the rigid spacers/bearings below the girders. The red bent caps and the testing frame was initially designed and used by Bradner et al (2010) to study hurricane waves but had to be modified in order to be able to withstand the tsunami waves.

Several experimental studies that have been conducted so far to evaluate the tsunami forces on bridges, modeled the tsunami waves either as solitary waves or bores. The solitary waves are easier to study due to their closed-form mathematical description and steady wave-shape, however the broken waves/bores might be more representative of the reality. Therefore, in this study both types of waves were tested in order to examine the sensitivity of the bridge response to the different wave types. Therefore, based on the CFD analyses a wave matrix was carefully selected which included two different wave depths, $1.90 \mathrm{~m}$ and $2.00 \mathrm{~m}$ and a range of wave heights from $0.36 \mathrm{~m}$ to $1.40 \mathrm{~m}$, shown in Table 1. A snapshot of a bore slightly before impacting the bridge is shown in Fig. 4.
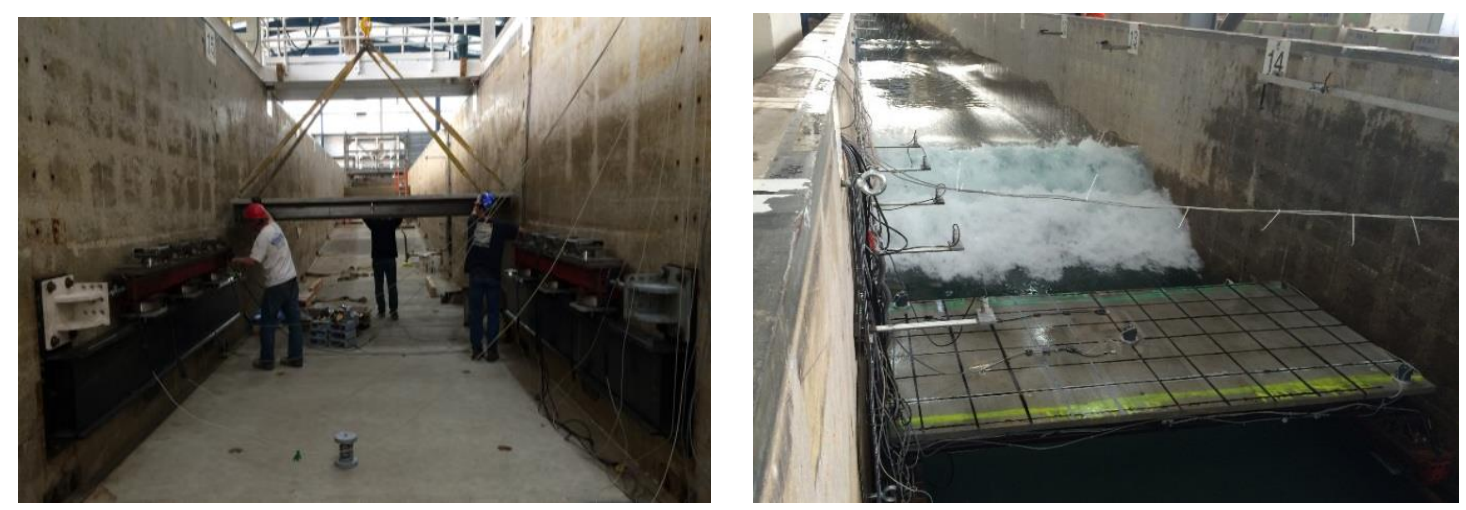

Figure 4. Installation of the bridge specimen on the bent caps (left) and turbulent bore slightly before impacting the bridge specimen (right)

\begin{tabular}{|c|c|c|}
\hline Water Depth (m) & Wave height $(\mathrm{m})$ & Wave Type \\
\hline \multirow{2}{*}{1.90} & $0.46-0.65$ & Solitary \\
\hline & $0.80-1.30$ & Bore \\
\hline \multirow{2}{*}{2.00} & $0.36-0.70$ & Solitary \\
\hline & $0.90-1.40$ & Bore \\
\hline
\end{tabular}




\section{Instrumentation}

Wave hydrodynamics were measured in the experiments using resistive-type wave gages, acoustic probes, pressure gages and ADVs. In particular, 13 resistive-type wave gages were installed along the length of the flume (Fig.3) to measure the free-surface elevation and capture the propagation of the waves (shoaling, breaking). Moreover, 5 ultrasound gages were installed at the location of the bridge to track the overtopping process, and 16 Vectrino-II ADVs were installed at four different locations in order to measure the flow velocities and determine the velocity profile. In addition, two pressure gages were added at the same location with two velocity profiles.

The bridge was extensively instrumented in order to measure the impact tsunami pressures and loads and record the bridge response. In particular, 12 pressure gages were installed on the steel girders and also on the concrete deck to capture the impact pressures at certain locations as shown in Fig. 5. In addition, 3 biaxial accelerometers together with 2 vertical and 2 horizontal string pots were installed on top of the concrete deck, to capture the bridge response in the horizontal and vertical axis. The accelerometers were installed at three locations on the top surface of the bridge deck, two of which were next to the offshore and onshore lifting lugs and the vertical string pots were installed at similar locations so that both type of instruments can capture the rotation of the bridge. The horizontal string pots were attached to stiff tubes that were bolted to the two bent caps to measure their displacements (Fig.5).

Furthermore, eight submersible load cells were installed below the girders and six submersible load cells were installed below the bent cap in order to measure the vertical forces in the girder and bent cap connections respectively. These six submersible load cells were also used as a mean for examining the accuracy of the recorded total vertical tsunami forces applied to the bridge and increase the reliability of the experimental data. Furthermore, two submersible load cells were installed horizontally at the level of the bent caps, to measure the total horizontal force transferred from the shear key to the bent caps and the supports. Apart from the above instruments, 24 strain gages were installed on the steel crossframes in order to get an estimation of the forces carried by each member. The bridge instrumentation is shown in Fig.5.

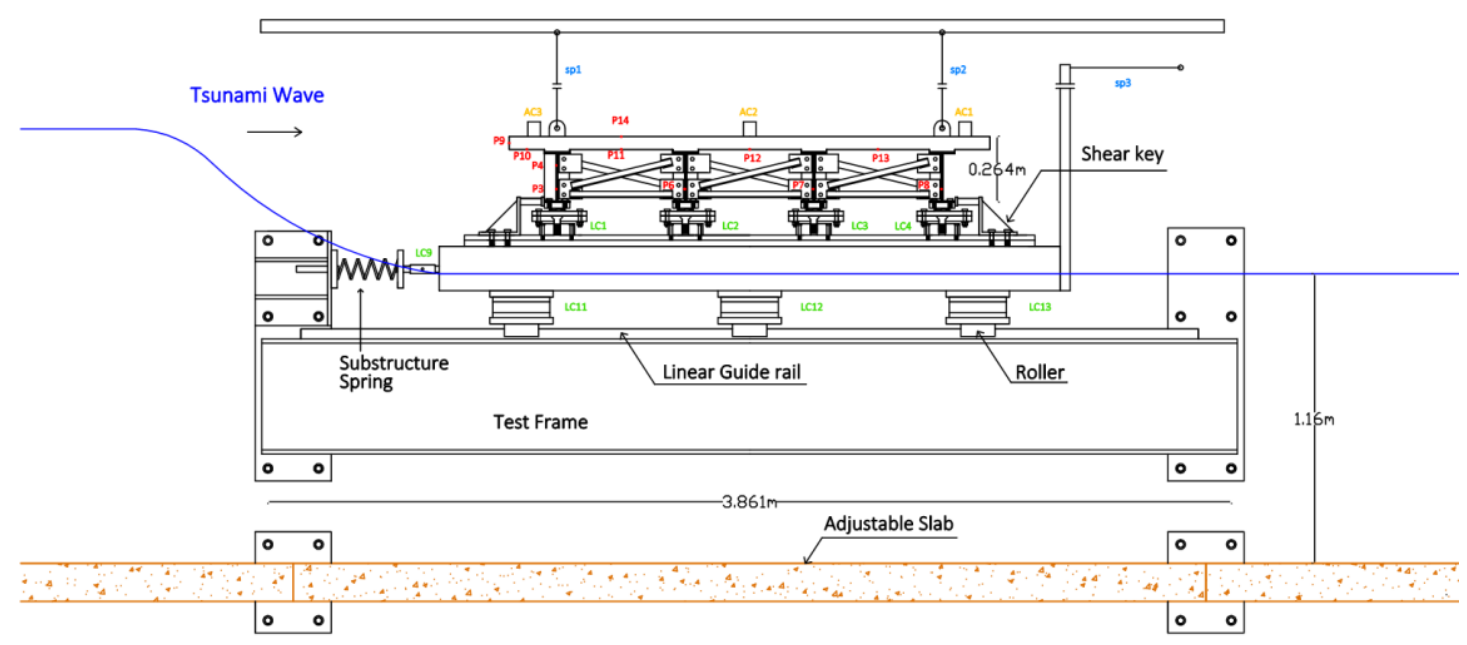

Figure 5. Cross-section of the experimental setup at the bridge location depicting the major components and the bridge instrumentation

\section{RESULTS}

\section{Test case ST2: Bridge with cross-frames}

This section will be focusing on representative experimental results for the bridge case ST2. For validation purposes of the generated solitary waves in the LWF, the recorded free-surface elevation at the first wave gage is compared against the theoretical values predicted by the equation 7.155 shown in Hughes (1993). As shown in Fig.7 the recorded free-surface elevation for the three different wave heights agree well with the theory. Fig. 8 is showing the wave propagation along the flume starting from 
wg1, which is located at the beginning of the flume close to the wavemaker and ending with wg13 which is located after the bridge. It can be interestingly noticed that the specific wave undergoes significant shoaling and the wave height increases by approximately $30 \%$ from wg2 to wg9, after which is breaks and loses energy. As recorded by wg12 by the time the wave reaches the bridge the solitary wave has transformed into a bore with a decreased wave height and a longer duration.
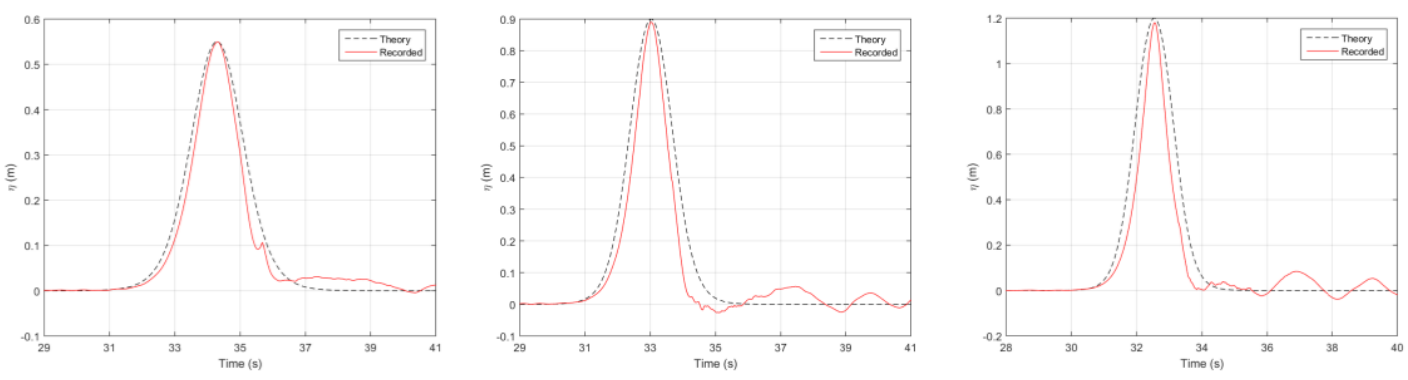

Figure 6. Theoretical (target) and recorded free-surface elevation at the wave gage close to the wave maker (WG1) for $\mathrm{H}=0.55 \mathrm{~m}$ (left), $\mathrm{H}=0.90 \mathrm{~m}$ (middle) and $\mathrm{H}=1.20 \mathrm{~m}$ (right)

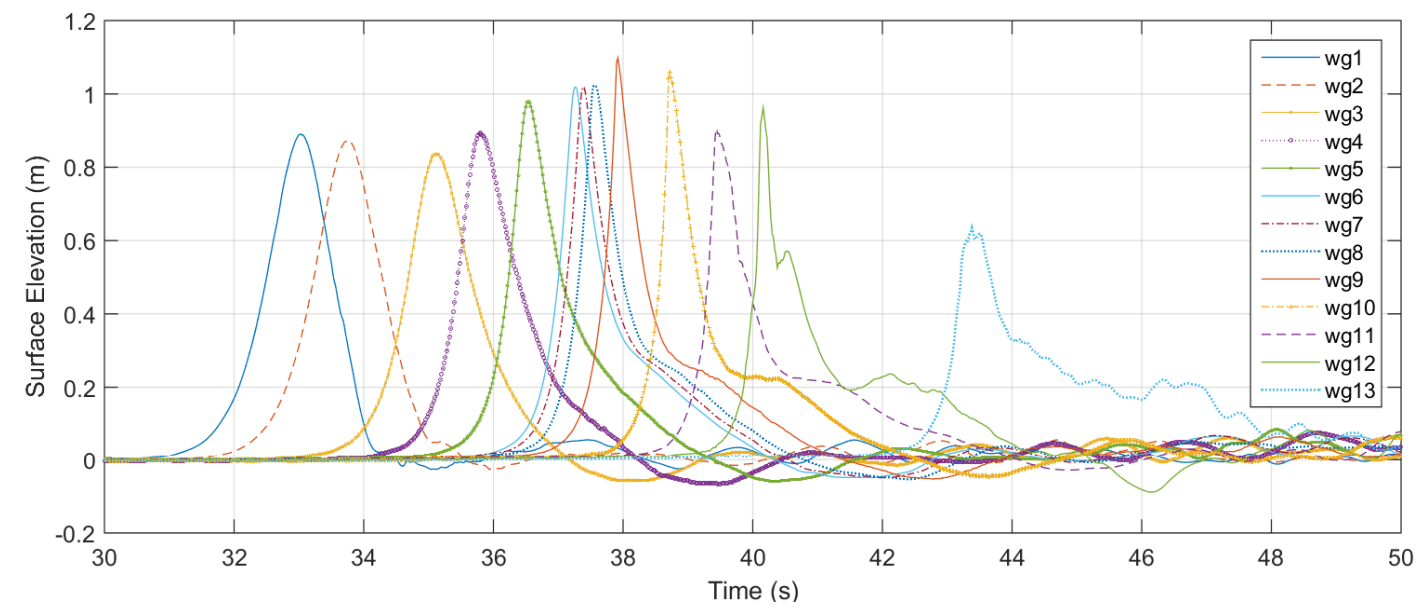

Figure 7. Surface elevation measured at different wave gages along the wave flume for $\mathrm{H}=0.90 \mathrm{~m}$

In Fig. 8 (top left) the vertical forces in the connections (elastomeric bearings) below each girder, as well as their summation, are plotted as a function of time. LC1+LC8 and LC4+LC5 are corresponding to bearings of the offshore and onshore girder respectively. Interestingly, in the force history, four different phases can be distinguished. Phase 1 is at the time of the first wave impact, where the offshore bearings are in tension (positive) and the onshore ones are in compression while the total vertical force is upwards (positive), indicating a large applied moment due to the applied horizontal and vertical tsunami load. Phase 2 is when the total vertical force becomes negative after the initial impact and then it fluctuates from negative to positive while the forces in some bearings have opposite signs than the others. Phase 3 has a longer duration that the first two phases and occurs when all bearings are going in tension indicating a governing vertical mode due to uplift. Phase 4 occurs towards the end of inundation when all bearings are in compression and the total vertical force is downward. These 4 Phases can also been observed in the bent cap connections as shown Fig.8 (top-right). 

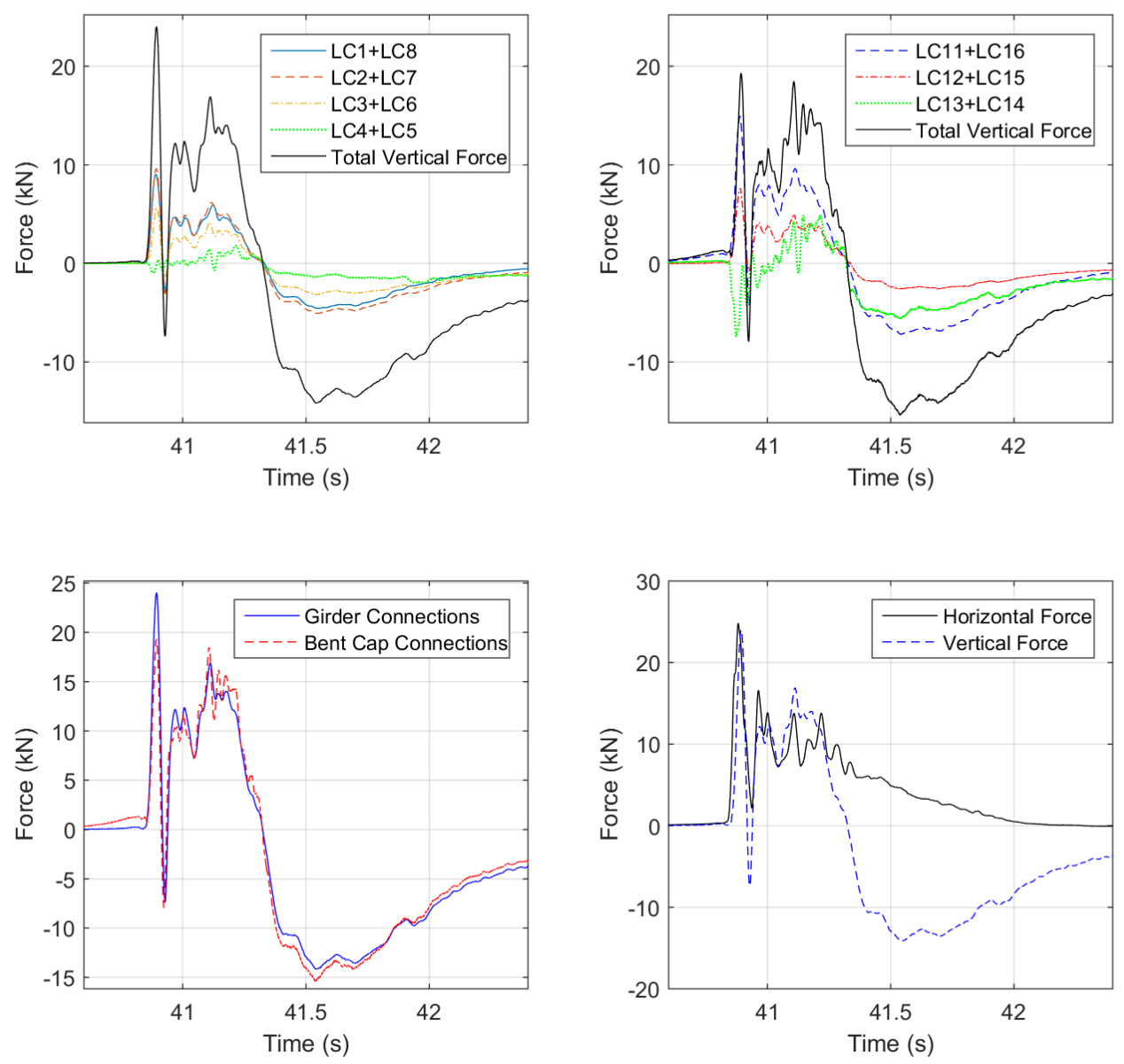

Figure 8. Vertical forces in the bearings (top-left) and in the connections below the bent cap (top-right), total vertical forces (bottom-left) and total horizontal and vertical wave forces (bottom-right) for $\mathrm{H}=0.90 \mathrm{~m}$

This graph demonstrates that during the passage of the wave though the bridge different structural modes are being excited, starting with a rotational mode along the longitudinal axis of the bridge at the time of the initial impact. This is due to the fact that the wave is a dynamic load that changes both magnitude and location in time. Until now, most of the researchers have been interested in the maximum total vertical load, however the experimental data in this study is indicating that attention should be given to the forces in the offshore bearings which are maximized during Phase 1. If the offshore bearings fail during Phase 1, then other bearings might follow, leading to a progressive collapse. The existence of the rotational mode associated with the large vertical forces in the offshore bearings had been identified previously by Istrati and Buckle (2014) via advanced FSI numerical analyses in LS-DYNA, and has now been verified with experiments.

The bottom-left graph of Fig. 8 is showing the total vertical forces recorded in the girder and bent cap connections and the horizontal force recorded in the link. The total vertical forces recorded in the girder and bent cap connections have a good agreement, with some differences, most likely due the bent cap dynamics and the transfer of some vertical force through the friction between the girders and the shear keys which is not captured by the load cells below the elastomeric bearings. The agreement of the total vertical force is observed for all the waves tested in the experiments increasing consequently the reliability of the recorded data. Last but not least, for this particular wave and test case the maximum horizontal force occurs at the time of the initial impact, approximately at the same instant that the vertical force is maximized, indicating the existence of a large applied moment on the bridge in the clockwise direction, which can justify the large forces in the offshore bearings. 

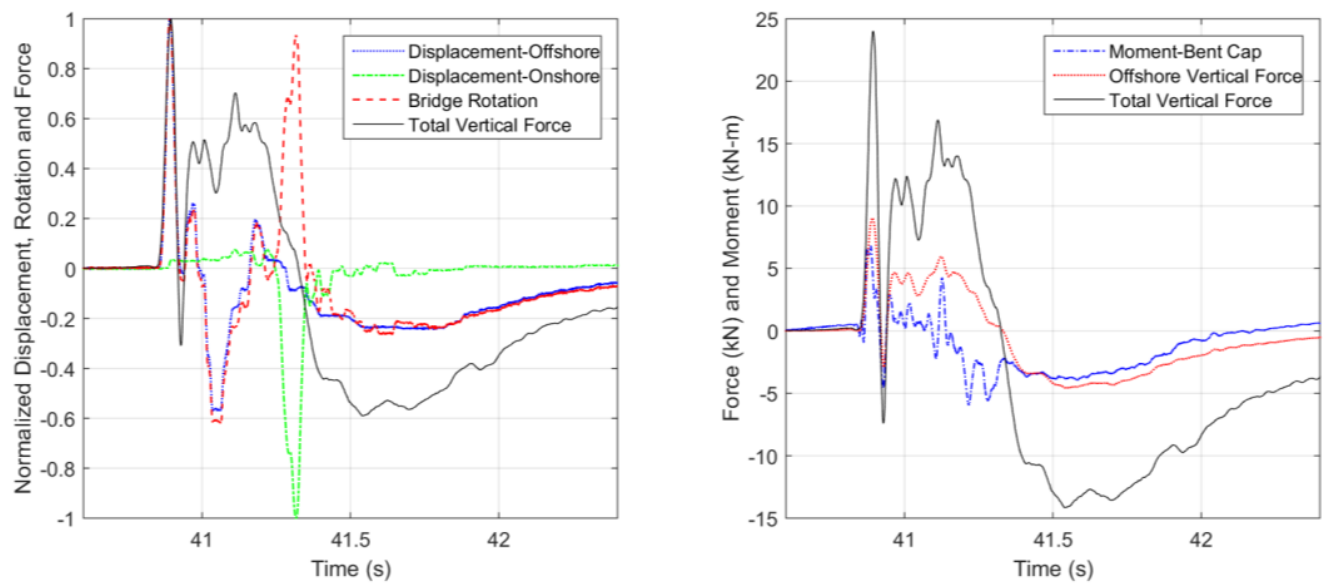

Figure 9. Normalized bridge displacements and rotation (left), vertical forces and moment in the connections (right) for a bore with $\mathrm{H}=0.90 \mathrm{~m}$

To gain a better understanding of the tsunami response of the bridge the rotation of the deck was calculated using the recorded vertical displacements. The time histories of the deck vertical displacements, rotation and total vertical force were divided by their maximum values and the normalized results are plotted in Fig.9 (left). As speculated in the previous paragraph, at the time of initial impact (Phase 1) both the offshore displacements and the rotation are reaching their maximum values. In addition, it can be clearly seen that as the wave inundates the bridge the direction of rotation changes starting with a clockwise direction (positive numbers on the graph) at the time of the first impact and switching to a counter-clockwise later one. Moreover, examination of the vertical displacements of the offshore and onshore girder reveals that the point of rotation at the time of the initial impact is close to the onshore girder. Last but not least, Fig. 9 (right) shows the moment calculated from the reaction forces in the connections, vertical force in offshore bearings and total vertical force in the bearings and it verifies that indeed the maximum vertical force in the offshore bearings occurs when the applied moment on the bridge is significant.

A significant conclusion form these graphs is that the slamming (transient) horizontal and vertical tsunami loads at the time of the initial impact of the bore on the bridge (Phase 1) create a large moment that is translated into large vertical forces in the offshore bearings. Interestingly these slamming wave loads in Phase 1 that are applied only on the offshore girder and overhang of the deck yield significantly larger bearing forces than Phase 3 where the quasi-static forces are applied on the whole deck. It must be noted however, that this is not true for all the waves tested in the experiments. The max total forces and max forces in the offshore bearings connections can occur in either Phase 1 or Phase 3 depending on the wave type and wave height, and therefore both phases should be examined for ensuring the tsunami resistance of bridges. There are complex underlying physics that determine a relationship between (i) the phase in which the maximum forces will occur and (ii) the wave type and wave height that impacts the bridge, and further investigation is required for identifying this relationship.

Fig. 10 shows the pressure below the bridge deck measured at different locations for a sample of unbroken (left graph) and bores (right graph). Location 1 corresponds to the offshore overhang and location 4 corresponds to the onshore chamber. This graph clearly shows that for all the examined wave cases the pressure below the offshore overhang is significantly larger than the pressures in the chambers. To obtain a more quantitative measure of the relationship between the vertical pressure at the offshore overhang and internal chambers, Tables 2 and 3 are showing the maximum recorded pressures at the overhang (press10) and in the middle chamber (press12) for a sample of unbroken solitary waves and bores respectively. These tables verify that the pressure at the overhang can be multiple times larger than the one in the middle chamber ranging from 2.84 to 19.25 times higher, with the larger values occurring for the smaller wave heights. 

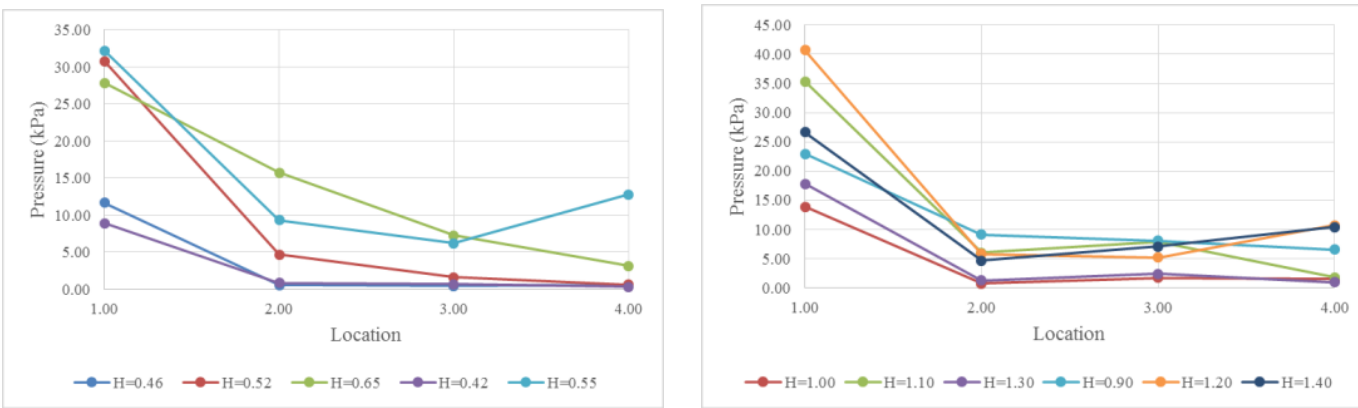

Figure 10. Maximum pressures recoded below the bridge deck at four different locations for unbroken solitary waves (left) and bores (right) of different heights

\begin{tabular}{|c|c|c|c|c|}
\hline $\mathrm{H}$ & $d$ & press 10 & press 12 & Ratio \\
\hline$(m)$ & $(\mathrm{m})$ & $(\mathrm{kPa})$ & $(\mathrm{kPa})$ & pr10/pr12 \\
\hline 0.52 & 1.90 & 30.78 & 1.60 & 19.25 \\
\hline 0.65 & 1.90 & 27.86 & 7.27 & 3.83 \\
\hline 0.42 & 2.00 & 8.94 & 0.70 & 12.70 \\
\hline 0.55 & 2.00 & 32.19 & 6.23 & 5.17 \\
\hline 0.70 & 2.00 & 61.34 & 16.84 & 3.64 \\
\hline
\end{tabular}

\begin{tabular}{|c|c|c|c|c|}
\hline $\mathrm{H}$ & $d$ & press 10 & press12 & Ratio \\
\hline (m) & $(\mathrm{m})$ & $(\mathrm{kPa})$ & $(\mathrm{kPa})$ & pr10/pr12 \\
\hline 1.00 & 1.90 & 13.87 & 1.73 & 8.00 \\
\hline 1.10 & 1.90 & 35.34 & 7.85 & 4.50 \\
\hline 1.30 & 1.90 & 17.82 & 2.36 & 7.56 \\
\hline 0.90 & 2.00 & 22.95 & 8.07 & 2.84 \\
\hline 1.20 & 2.00 & 40.74 & 5.20 & 7.84 \\
\hline 1.40 & 2.00 & 26.62 & 7.09 & 3.75 \\
\hline
\end{tabular}

\section{Bridge with cross-frames (ST2) vs. Bridge with diaphragms (ST5)}

\section{Time histories for a selected wave height}

This section will focus on the comparison of the bridge cases ST2 and ST5 in an attempt to identify the differences in the tsunami loads that bridge with cross-frames and bridge with diaphragms have to withstand. The main difference between the two specimens is that the second specimen has plywood sheets attached at the locations of the intermediate and end cross-frames and is expected to trap the air between these sheets and the girder during inundation. In the first part comparison of the time histories for an unbroken solitary wave with $\mathrm{H}=0.42 \mathrm{~m}$ are presented, and in the second part the maximum values of pressures and forces for a sample of waves are presented.

Fig. 11 shows a comparison of the free-surface recorded close to the wavemaker (left graph) and at bay 12 which is close to the bridge (right graph) for the two different bridge configurations. The generated waves seem to be similar, allowing us to proceed with the comparison of pressures and forces. This comparison is shown in Fig. 12, where it can be seen that the pressures on the offshore girder (top-left graph) and overhang (top-right graph) are fairly similar, which was expected since the overhang and the offshore girder are identical in both bridge cases. In contrast, the horizontal pressure on the internal girder next to the offshore one (bottom-left graph) and the vertical pressure below the deck (bottom-right graph) in the same chamber are totally different in bridges case ST2 and ST5. One of the main differences lie in the fact that in ST5 the pressures at both locations (girder and deck) are reaching a maximum value before they do in ST2. This is most likely because in bridge case ST5 there is significant air entrapment between the girders, diaphragms and the wave, which actually transfers the pressures on the girder and the deck before the wave reaches the girder or the bottom of the deck. 

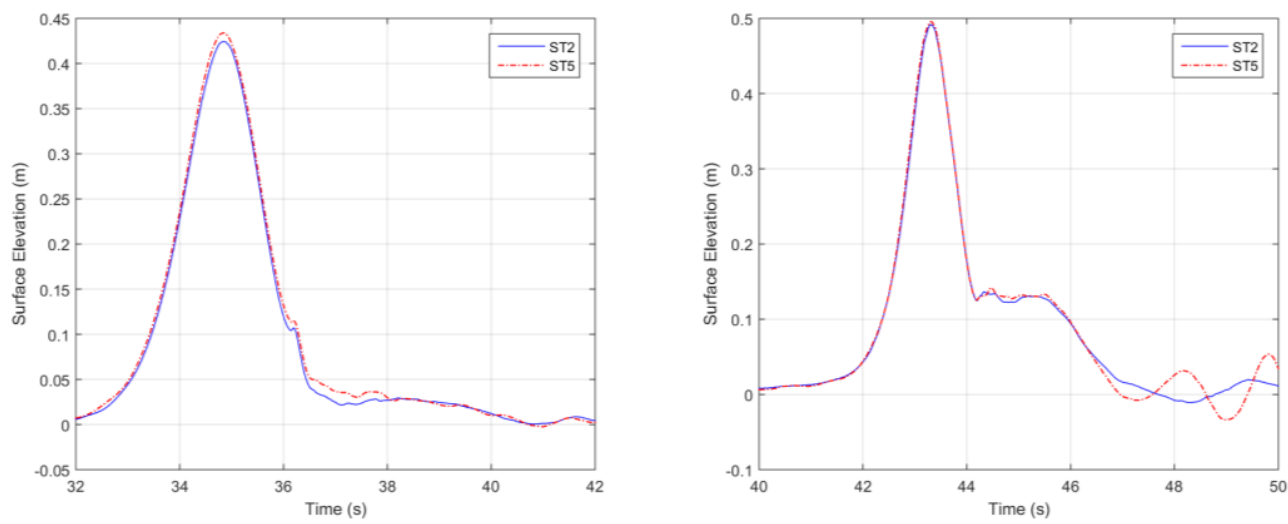

Figure 11. Surface elevation at the wave gage close to the wavemaker (left) and close to the bridge (right)
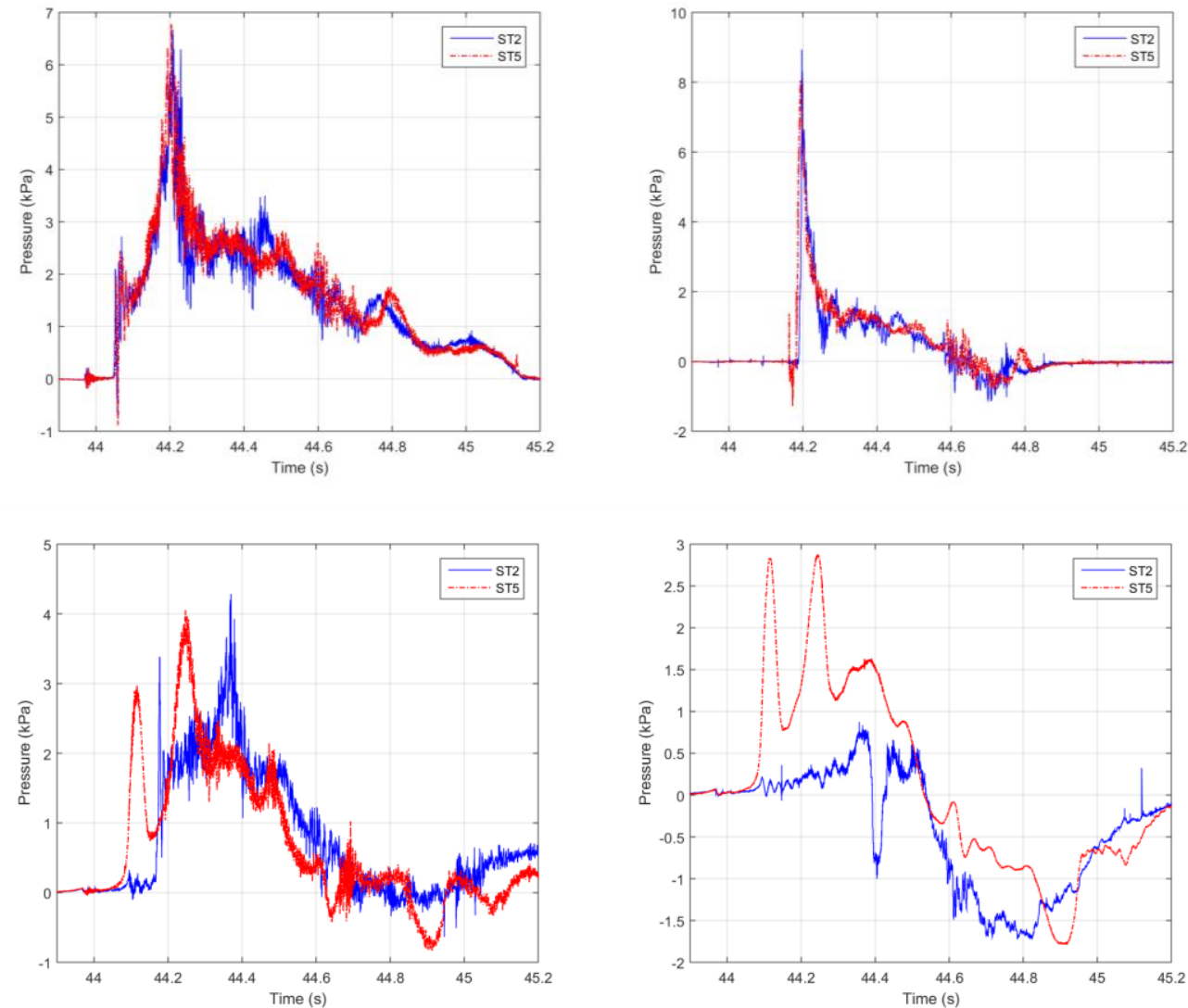

Figure 12. Pressure on the offshore girder (top-left), below the deck at the overhang (top-right), on the internal girder next to the offshore girder (bottom-left) and below the deck in the $1^{\text {st }}$ chamber (bottom-left) for $\mathrm{H}=\mathbf{0 . 4 2 m}$

As shown in Fig. 12 another difference between the two specimens is the fact that the bridge with diaphragms (ST5) has two distinctive peaks in both the pressures on the girder and on the deck and can probably be related to the wave-air interaction and the cushioning effect due to the compressibility of the air as the wave inundation proceeds. When it comes to the magnitude of the pressure the air entrapment seems to have a minor effect on the horizontal pressure and a major effect on the vertical pressure on the deck, with ST5 witnessing approximately 3 times higher vertical pressures due to the air entrapment. In addition, the air entrapment seems to be smoothing out the peaks of the pressure histories and increase their duration, as was also seen in the experimental study by Cuomo et al (2009).

Figure 13 shows the horizontal forces (left graph) recorded in the link and the total vertical forces recorded in the bent cap connections (right graph). Inspection of the graphs reveals that there is no 
significant difference in the maximum horizontal forces and this is because the maximum value occurs at the time of the initial impact - in Phase 1- where the trapped air has no effect, however as the wave inundation progresses the air entrapment and the wave-air interaction seems to alter the force history by smoothing some of the peaks. When it comes to the vertical forces, the air entrapment in the bridge with diaphragms causes a significant increase of $73 \%$ for the particular wave height and introduces two distinct peaks (uplift) in the time histories.
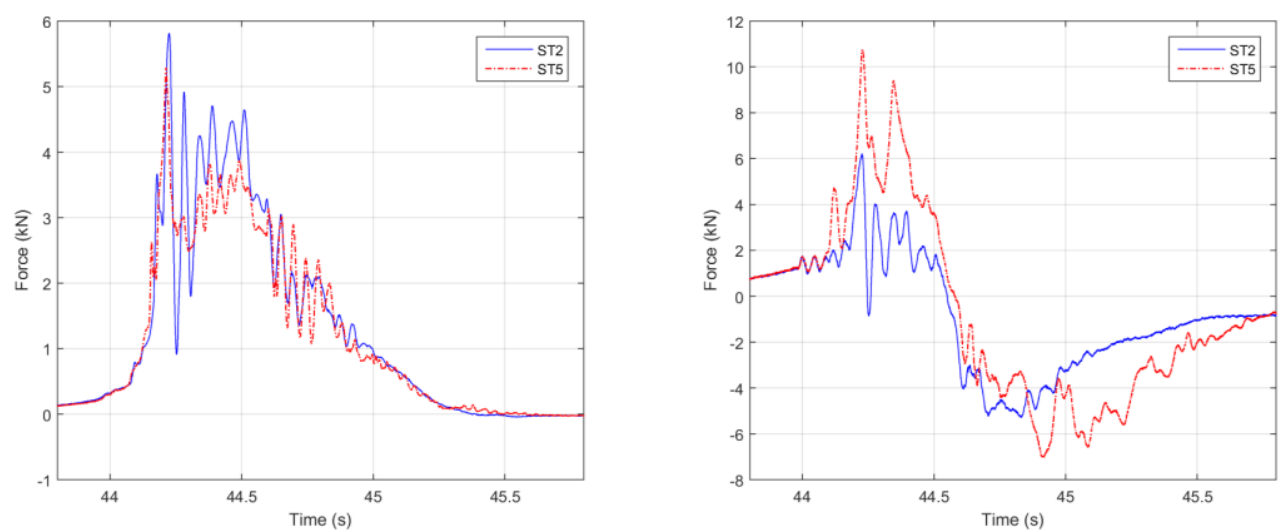

Figure 13. Total horizontal forces recorded in the link (left) and total vertical forces recorded in the bent cap connections (right) for $\mathrm{H}=\mathbf{0 . 4 2 m}$

\section{Maximum values for solitary waves and bores}

In order to develop a better understanding of the role of air entrapment, the maximum values of two parameters of interest have been plotted as a function of the wave height. In particular, in Fig.14 the pressures below the deck in the offshore and middle chambers have been plotted for unbroken solitary waves and bores that were tested at a $2.0 \mathrm{~m}$ water depth. In these graphs the bores correspond to initial wave heights starting from $0.90 \mathrm{~m}$ and larger. It must be noted that although in the time-histories of the previous section the air-entrapment increased the pressure in the middle chamber by a factor of 3 for a $0.42 \mathrm{~m}$ wave height, this is not true for all the chambers and all wave heights, as seen in Fig. 14. For example, in the middle chamber the pressures for all the wave heights apart from the $0.70 \mathrm{~m}$ and $0.90 \mathrm{~m}$ show an increase due to the air entrapment, however this trend is not the same in the offshore chamber, where the air-entrapment has a variable effect for different wave heights. This variable effect might be due to the fact that the air entrapment modifies the wave flow differently each time leading to a complex nonlinear wave-air interaction phenomenon.
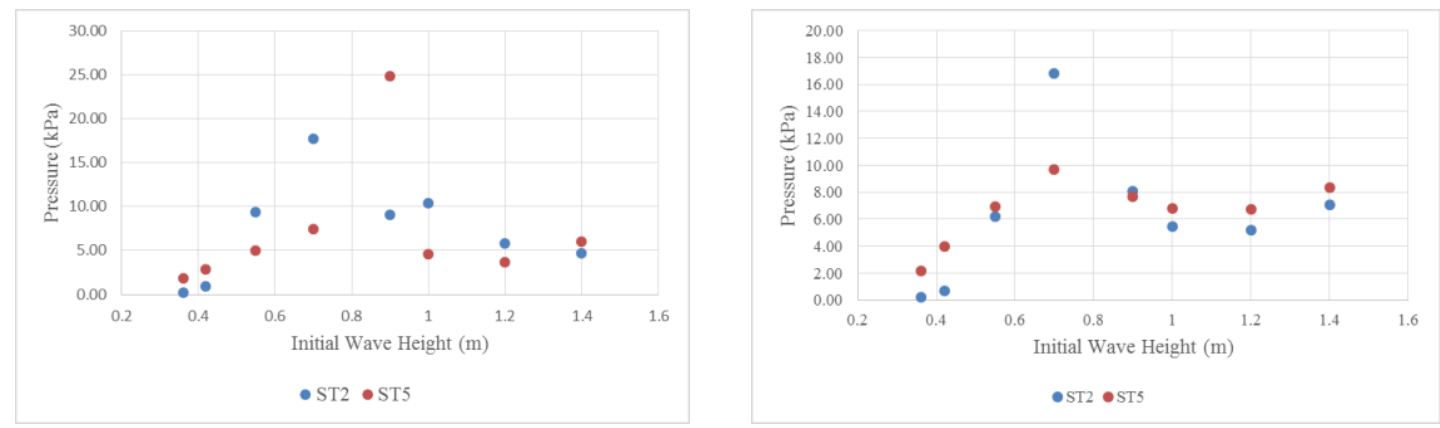

Figure 14. Maximum pressures below the deck in the offshore chamber (left) and in the middle chamber (right) for all the wave heights tested for a $2.0 \mathrm{~m}$ water depth. 


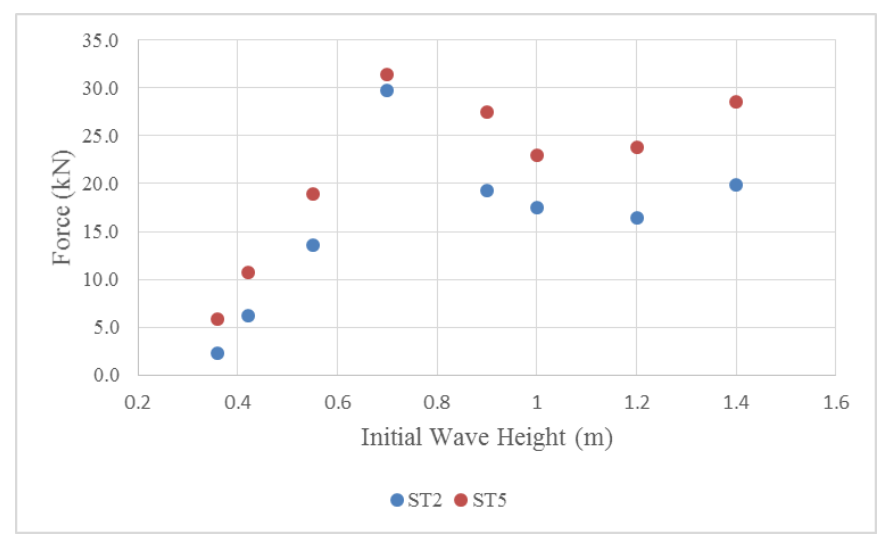

Figure 15. Maximum total vertical forces in the bent cap connections for wave heights tested for a $2.0 \mathrm{~m}$ water depth.

The last figure in this study, Fig. 15 shows the total vertical forces recorded in the bent cap connections for solitary waves and bores of different wave heights. Interestingly the air entrapment seems to have a consistent effect increasing the total vertical forces for both solitary waves and bores. However, the exact amount of increase in the forces depends again on the wave height. A possible explanation for this observation is that in the case of the bridge with cross-frames for some wave heights the maximum vertical force occurs in Phase 1 where the slamming (hydrodynamic) component is governing, while in the case of the bridge with diaphragms for most of the wave heights the maximum force occurs in Phase 3 where the quasi-static (hydrostatic) component is governing, making it hard to decipher the underlying physics by just examining the maximum values. Therefore, further post-processing of the experimental data is required. It must be noted though that the largest increase of the vertical forces occurs for the smaller solitary waves that do not reach the bottom of the deck and therefore the pressure is transferred through the trapped air. For example for the smallest solitary wave with $\mathrm{H}=0.36 \mathrm{~m}$ the total force increased by a factor of 2.5. Last but not least examination of Fig. 14 and Fig. 15 demonstrates that comparison of the pressures in a certain chamber at the midspan (far from the end diaphragms) cannot adequately describe the effect of the escape and entrapment of the air on the total vertical forces. This indicates that the 3D effects are significant and that the pressures close to the end cross-frames or diaphragms are significantly different than the applied pressures at the mid-length of the bridge.

\section{SUMMARY AND CONCLUSIONS}

In this study large scale (1:5) hydraulic experiments of different configurations of a straight bridge were conducted in the LWF at Oregon State University. The bridge was subjected to both solitary waves and turbulent bores to identify the differences in the force patterns associated with different wave types. Extensive instrumentation was used to record both the hydrodynamic characteristics and the response of the bridge, and high quality data was obtained that can prove useful for gaining a direct insight into the physics of the tsunami effects on bridges. In addition, this data can be used for calibration and validation of hydrodynamic models. Preliminary examination of the data has shown that:

- Four different phases seem to exist in the vertical force histories, among which (i) a phase with a large moment and a distinct rotational bridge mode at the time of the first impact of the tsunami wave on the bridge, (ii) a phase with a governing uplift mode of the bridge during the passage of the wave through the bridge and (iii) a phase with a downward force towards the end of the inundation.

- Special attention should be given to Phase 1 because for most solitary waves and bores impacting the bridge with cross-frames this phase introduced the largest tension in the offshore bearings due to the simultaneous large horizontal and vertical slamming components of the applied tsunami load. Most of the research work conducted in this field to date has focused only on the maximum total force which can occur in either Phase 1 or Phase 3, however examining only the maximum total force might not be adequate because if the offshore bearing exceed their vertical capacity in Phase 
1 (initial impact) and get damaged then the vertical loads would be redistributed to the remaining bearings with the possibility of leading to a "progressive collapse mechanism" that will eventually result in the washout of the bridge.

- For all the examined wave cases the pressure below the offshore overhang is significantly larger than the pressures in the chambers. In particular, the pressure at the overhang can be multiple times larger than the one in the middle chamber ranging from 2.84 to 19.25 times higher, with the larger values occurring for the smaller wave heights.

- The air entrapment occurring in the bridge with diaphragms can alter significantly the wave flow in the chambers compared to the bridge with cross-frames and introduce a different pattern of pressures on the girders and below the deck. In particular, when air-entrapment was present, these pressures histories (i) reached their maximum values before the wave reached the girder and the deck, most likely because the wave pressure was transferred to the structural components through the compressed air, (ii) had two characteristic peaks, smoother and with a longer duration than the case without air entrapment, probably due to the nonlinear wave-air interaction and the cushioning effect.

- The air entrapment had a consistent effect on the total uplift forces recorded in the bent cap connections increasing the maximum uplift forces for both solitary waves and bores. However, the exact amount of increase of the vertical forces was seen to depend on the wave height, with the largest increase of the vertical forces occurring for the smaller solitary waves that do not reach the bottom of the deck.

- The effect of the air entrapment on the maximum values of the pressures in the chambers was not consistent for all the wave heights as was the case with the total uplift force, resulting in an increase of pressures for certain wave heights and a reduction of pressure for other ones. This variable effect on the pressures demonstrates that examination of the pressures at the mid-length of the bridge in a certain chamber cannot describe adequately the role of the escape and entrapment of the air on the total uplift forces and that 3D effects are significant in these phenomena.

\section{ACKNOWLEDGMENTS}

This research project was funded by the Federal Highway Administration under Contract No. DTFH61-07-C-0031. Authors wish to thank Patrick Laplace, Tao Xiang, Tim Maddux and the staff of Hinsdale Wave Research Laboratory at Oregon State University for their assistance during the experiments.

\section{REFERENCES}

Azadbakht Mohsen. 2013.Tsunami and hurricane wave loads on bridge superstructures. PhD dissertation, Oregon State University.

Bozorgnia M., J.J. Lee, \& F. Raichlen. 2011. Wave structure interaction: Role of entrapped air on wave impact and uplift forces, Coastal Engineering Proceedings, 1(32), 57.

Bradner C, Schumacher T, Cox D, Higgins C. 2010: Experimental setup for a large-scale bridge superstructure model subjected to waves. Journal of waterway, port, coastal, and ocean engineering, 137(1), pp. 3-11.

Bricker JD, Nakayama A. 2014. Contribution of trapped air, deck superelevation, and nearby structures to bridge deck failure during a tsunami. Journal of Hydraulic Engineering, 140(5), 05014002

Cuomo, G., Shimosako, K. I., \& Takahashi, S. 2009. Wave-in-deck loads on coastal bridges and the role of air. Coastal Engineering, 56(8), 793-809.

EERI Special Earthquake Report-October 2011. Learning from Earthquakes: Bridge Performance in the Mw 9.0 Tohoku, Japan, Earthquake of March 11, 2011.

Hallquist JO (2014): LS-DYNA Theoretical Manual. Livermore Software Technology Corporation, Livermore, $\mathrm{CA}$

Hayashi H. 2013. Study on tsunami wave force acting on a bridge superstructure. Proc 29th USJapan Bridge Engineering Workshop, Tsukuba, Japan.

Hayatdavoodi, M., Seiffert, B. and Ertekin, R. C. 2014. Experiments and computations of solitarywave forces on a coastal-bridge deck. Part II: Deck with girders," Coastal Engineering, 88, 210-228 
Hayatdavoodi M, Ertekin RC. 2015a. Wave forces on a submerged horizontal plate. Part I: Theory and modelling. J. Fluids and Structures, 54(April), pp. 566-579.

Hoshikuma J, Zhang G, Nakao H, Sumimura T. 2013. Tsunami-induced effects on girder bridges. Proc of the International Symposium for Bridge Earthquake Engineering in Honor of Retirement of Professor Kazuhiko Kawashima, Tokyo, Japan.

Hughes SA.1993. Physical models and laboratory techniques in coastal engineering. Advanced Series on Ocean Engineering, Vol. 7, World Scientific Publishing, Singapore.

Istrati D, Buckle IG. 2014. Effect of fluid-structure interaction on connection forces in bridges due to tsunami loads. Proc 30th US-Japan Bridge Engineering Workshop, Washington DC, United States.

Kataoka S, Kaneko M. 2013. Estimation of Wave Force Acting on Bridge Superstructures due to the 2011 Tohoku Tsunami. Journal of Disaster Research Vol. 8.

Kawashima K. 2012. Damage of bridges due to the 2011 Great East Japan Earthquake. Proc Int Symp on Engineering Lessons Learned from the 2011 Great East Japan Earthquake, March 1-4, 2012, Tokyo, Japan.

Kawashima, K. and I. Buckle, I. 2013. Structural performance of bridges in the Tohoku-Oki earthquake. Earthquake Spectra, 29(S1), pp.S315-S338.

Kosa K. 2012.Damage analysis of bridges affected by tsunami due to Great East Japan Earthquake. Proc Int Symp on Engineering Lessons Learned from the 2011 Great East Japan Earthquake, March 1-4, 2012, Tokyo, Japan.

Lau TL, Ohmachi T, Inoue S, Lukkunaprasit P. 2011.Experimental and Numerical Modeling of Tsunami Force on Bridge Decks. DOI: 10.5772/23622.

Martinelli L, Lamberti A, Gaeta MG, Tirindelli M, Alderson J, Schimmels S.2010.Wave Loads on Exposed Jetties: Description of Large-Scale Experiments and Preliminary Results. Proc of the Int Conference on Coastal Eng; No 32.

Maruyama K, Tanaka Y, Kosa K, Hosoda A, Mizutani N, Nakamura T. 2013. Evaluation of tsunami force acted on bridges by Great East Japan Earthquake. 10 CUEE Conf Proc, Tokyo, Japan.

McPherson, R.L.2008. Hurricane induced wave and surge forces on bridge decks, PhD dissertation, Texas A\&M University.

Seiffert B, Hayatdavoodi M, Ertekin, RC. 2014. Experiments and computations of solitary-wave forces on a coastal-bridge deck. Part I: flat plate. Coastal Engineering, 88, 194-209.

Seiffert, B., R. C. Ertekin, and I. N. Robertson. 2015. Effect of entrapped air on solitary wave forces on a coastal bridge deck with girders. Journal of Bridge Engineering 21.2: 04015036

Takahashi, S., K. Tanimoto, and S. Miyanaga. 1985. Uplift wave forces due to compression of enclosed air layer and their similitude low. Coastal Eng. Jpn 28 (1985): 191-206.

$\mathrm{Xu}$, G., C. S. Cai, and Q. Chen. 2016. Countermeasure of Air Venting Holes in the Bridge DeckWave Interaction under Solitary Waves. Journal of Performance of Constructed Facilities: 04016071.

Yashinski M. website: http://www.bridgeofweek.com/

Yim SC, Boon-intra S, Nimmala SB, Winston HM, Azadbakht M, Cheung, KF.2011. Development of a Guideline for Estimating Tsunami Forces on Bridge Superstructures. Oregon Dept of Transportation Report, No. OR-RD-12-03. 